Open Access

\title{
Using the Appraisal framework to analyze source use in essays: a case study of engagement and dialogism in two undergraduate students' writing
}

Miki Mori®

Correspondence:

miki.mori@univ-mayotte.fr

Centre Universitaire de Formation et Recherche (CUFR) de Mayotte,

Dembeni, France

\begin{abstract}
A key element of academic writing involves incorporation of external voices, which is a complex rhetorical and linguistic task. Student writers must face this challenge of using sources to strengthen their own arguments. Appraisal, specifically Engagement, provides a useful framework for analyzing source use in texts, as it considers evaluation and dialogic voicing. This article describes a semi-ethnographic case study that contrasts two undergraduate writers and their writing drafts. Results show similarities and differences based on the linguistic abilities of the students and their experience in writing, but overall improvement in terms of dialogic voicing in the final drafts. Applications to research and instruction for ESL and mainstream writing are discussed.
\end{abstract}

Keywords: Appraisal, Citation, Academic writing, ESL, Dialogism, Bakhtin, Engagement, SFL, Source use

\section{Introduction}

"I struggled with this because I didn't know how to tie things into sources and additionally, umm, personal experience."

-Mara

"I have a hard time adding some of my own comment in the paper... because I am unfamiliar with the topic. Also, in that particular paragraph that lacks my own opinion, I was not sure how I was going to remove some of the in-text citations."

-Wes

The above quotes come from two undergraduate students discussing their incorporation of outside texts such as research articles, books and websites in a research project. Mara had trouble blending literature and research with her own experiences, whereas Wes had little experience with his research topic and therefore struggled to include his voice in a conversation with the literature. Both grappled with how to write a research-based text that weaved in the voices of outside sources with their own voices. Those who have passed through academia or who teach academic writing may find this struggle familiar, as source incorporation proves itself challenging not just for formatting and citation, but also because of the difficulties in creating a dialogue

(c) The Author(s). 2017 Open Access This article is distributed under the terms of the Creative Commons Attribution 4.0 International License (http://creativecommons.org/licenses/by/4.0/), which permits unrestricted use, distribution, and reproduction in any medium, provided you give appropriate credit to the original author(s) and the source, provide a link to the Creative Commons license, and indicate if changes were made. 
among many authors. Dialogism finds itself as one of the pillars of the theories used in the Appraisal framework (Martin \& White, 2005; White, 2003), as seen with the notion that "no utterance is an island" ("Engagement- a Bakhtinian perspective," 2015, para. 4), which itself refers to the English poet John Donne's words that "no man is an island." All utterances or ideas find themselves in conversation with past literature or ideas. The academic research paper exemplifies this idea with its heavy reliance on past research for ideas, findings and wording. Yet, as seen with Mara and Wes, constructing this dialogue proves challenging.

I met Mara and Wes while researching source use in writing and worked with them as a writing tutor. Mara, a native English speaker, wrote strong papers and despite her struggles, incorporated outside sources effectively. Wes, a non-native English speaker, used outside sources less effectively and seemed unsure of how to write a strong research-based paper. While working with them and analyzing their writing, I found that the concepts and methods of Appraisal, particularly Engagement, were useful for understanding the research-writing process with source incorporation. Appraisal looks at the fine details of writing, such as verb choice, and thinks about the ideas expressed in a citation. The goals of this paper are twofold: to demonstrate, through an Appraisal lens, how two different writing students engaged outside sources in a writing text; and to discuss how Appraisal and Engagement can be used by those who teach writing to help students effectively incorporate outside sources, termed external voices in the framework.

\section{Literature review}

\section{Source use in writing}

Before considering the Appraisal framework, it is important to consider the larger context of source use in academic texts, which has been extensively researched according to genre (Cao \& Hu, 2014), discipline (Hyland, 2005), and writer (novice vs. expert, native vs. non-native speakers) (Lee, 2010; Petrić, 2012; Swales, 2014). In general, source use, including use of quotations, varies by discipline and type of writer. Nevertheless, novice writers must acquire such language and views on the world, such as disciplinespecific vocabulary and writing styles that highlight the object of study rather than the researcher. In their foundational research on source use and variation, $\mathrm{Hu}$ and Wang (2014) notably speculate that these differences may occur due to epistemological differences between the domains of sciences and humanities, with positivist approaches in the sciences emphasizing facts and truth while non-positivist approaches in the social sciences and humanities emphasize subjectivity and multiplicity of truths.

Overall, though variation based on subject matter exists, students receive higher marks when they incorporate sources in a woven manner, including critical analysis and application of the source's arguments to their own. Incorporation and integration may refer to paraphrasing and summarizing (Lee, 2010) or perhaps quoting in ways that require syntactic manipulation of the cited text (Petrić, 2012). Moreover, Lee (2010) found that higher-scoring texts that maintained authorial voice were not crowded with other source's ideas or words. The student writers also used sources to advance their own arguments without closing down the conversation with the reader. Student texts receiving low grades (typically Cs or Ds) did not integrate their sources in such a matter and tended to not only populate their texts with more direct 
quotes but also used sources in a less cohesive, woven manner, which Swales (2014) calls "parenthetical plonking" (p. 135), in which a cited source is put in a text but not discussed or framed.

Students struggling with academic writing may lack the ability to use intertextuality as a strategic device and create a woven text (Lee, 2010) and struggle with incorporating other's ideas and words with their own (Gu \& Brooks, 2008). Understandings of the use of sources may also be a factor (Hutchings, 2014), which is important considering Hyland's (2000) research findings that the number of references in an academic text has increased and "they have become more focused, pertinent and integrated into the argument" (p. 22). Developing discipline-specific practices for using sources remains essential for students' integration into the academic community. This is because language is always a socially embedded practice where a particular group of individuals construct language in a particular fashion, thus creating a specific genre (Bakhtin, 1986). Student writers participate in this social group when they incorporate outside sources in ways similar to their disciplines.

\section{Engagement with source texts}

In addition to participating in a social practice of a discipline, student writers like Mara and Wes are asked to interact with source authors by creating a dialogue. When using an outside source (henceforth called external voice), they must respond to the author's ideas and/or words. Response and dialogue involve another key activity, which is termed Engagement. Generally speaking, engagement means having some sort of active interaction with a person, group or written text, such as finding a particular book and writing style to be engaging. A class discussion of a controversial topic may result in students being particularly involved in their peers' responses, which is an activity that could be considered engaging. However, engagement has also been interpreted to indicate a person's opinion, stance, or attitude towards an idea or person (Martin \& White, 2005). I adapt this definition in this study.

For example, in a review of previous research on a topic, a writer may only partially agree with the conclusions drawn from a particular study. In this case, use of particular epistemic (degree of certainty regarding what is) and deontic (propositional) modals would indicate the degree to which the writer endorses the proposals, such as the implications may only be partially accurate or the design should have considered. In these expressions, the writer works to partially limit the conclusions made about the study by stressing his/her opinion as the more valid one. Researchers understand this activity to be a part of engagement in which a particular piece of text recognizes other possibilities or narrows down the options, a concept termed dialogic expansion and dialogic contraction (White, 2003). Dialogic expansion is when multiple opinions are discussed and dialogic contraction involves a conversation limited to the authorial voice (the student writer). White (2003) considers dialogic expansion and contraction as two ends of a continuum which describes discourse and how open or closed it is to considering the opinions of others. Dialogically contractive statements, such as everyone knows or it is a fact, serve to limit possibilities for legitimate disagreement. On the opposite of the continuum are dialogically expansive statements that invite listeners and readers to consider alternative realities, as seen in some believe that or theorists propose. 
Notably, dialogic contraction is not always a rhetorically harmful act; in order to make an argument, writers have to dialogically contract the discussion with the reader to focus on the soundness of their argument. For example, depending on the intended source function, a student can more neutrally discuss the external voices's ideas such as with some researchers argue... or they can express their agreement with the idea as with As $X$ has so compellingly demonstrated ("Dialogic expansion and contraction," 2015, para. 3). In the former, the student opens up the conversation to other's arguments, whereas in the latter $\mathrm{s} / \mathrm{he}$ contracts the dialogic space. If the external voice is a particular authority on an issue, it may be rhetorically valuable to employ the latter type of source use, since "the writer...adds to the argumentative force by representing the current view as one which is not theirs alone but one which is shared with, for example, the wider community or with relevant experts" ("Dialogic expansion and contraction," 2015, para. 3).

Nonetheless, it appears dialogic expansion is an important part of academic writing, since expansion acknowledges other possibilities and findings. However, novice writers have been found to approach the topic of an argument as if their opinion were the sole (correct) one, resulting in a "constriction of negotiation of space" (Mei \& Allison, 2005). In the act of forming an argument in an academic text, student writers need to be able to identify their position on a topic as part of an established discussion. Considerations must be made as to whom they are writing as well as how others' findings and ideas relate to their argument. There are many ways to do this and it is a complex web of linguistic and rhetorical moves to indicate attitude to a reader about a topic and other people's thoughts. Across genres, a published academic text "display[s] the writer's awareness of both its readers and its consequences" (Hyland, 2005, p. 5). In this sense, a writer is recognizing the addressivity in writing, where an author considers whom $\mathrm{s} /$ he is responding to or addressing (Bakhtin, 1986). At the same time, writers must ensure that their "voice is not lost, though the diversity of opinions is acknowledged" (Mei \& Allison, 2005, p. 115).

Discussions of reporting information and expressing (or not) attitude and stance bring to question the notion of neutral statements and objective writing. Though there are ways to incorporate an external voice in a fairly unbiased manner, in the end the source is contributing to the authorial voice's argument as a whole, which includes some sort of stance. It seems that there is always a stance being taken no matter how subtle (Bakhtin, 1986; "Engagement- a Bakhtinian perspective," 2015), and it is expressed linguistically, including when incorporating external voices. When taking a stance, a student writer might consider the audience and external voice while thinking about his/her agreement with the proposed ideas. In this sense, s/he responds to another person and creates a discussion. That is, the ways student writers incorporate their sources and the ways in which they express attitude contribute to the creation of a dialogue.

Importantly, elements of effective texts are not just based on ratios or a binary of dialogic expansion or contraction. How students employ their sources matters. To illustrate, Mei's (2007) study of undergraduate geography essays found that how students conversed with their sources correlated with grading and not solely expansive or contractiveness alone. For example, for dialogically expansive texts, those with the higher grade engaged their sources with attribution, which is discussing what others have 
done; in many respects, the students situated their essays within a previously established academic conversation and they explicitly demonstrated their participation in it by attributing ideas and texts to others. However, low-grade essays that were dialogically expansive tended to entertain ideas and possibilities without reference to other sources. In addition, for dialogically contractive texts, students who received lower grades tended to close down the conversation by pronouncing their own ideas as true. When high scoring essays were contractive, they closed down the conversation in terms of addressing a claim from others and countering it (Mei, 2007). However, given the various ways in which sources can be dialogically expansive or contractive (Martin \& White, 2005), it remains to be seen how a more refined understanding of dialogism may help with categorizing source use.

Response to an external voice can be considered beyond expansion and contraction of dialogue. The response also involves a stance, which can range in assertiveness; the benefit of this range is that it allows for a writer to cater an argument towards specific circumstances such as audience, purpose, evidence, etc. This aspect of source incorporation has been researched as well. To illustrate, other studies also use the context of high- and low-grade essays to look for patterns in texts. In general, students make their arguments too assertive (Mei \& Allison, 2005) without evidence to justify their claims (Allison, 1995; Lee, 2010), and this is particularly true of those receiving lower grades regardless of L1 or L2 English backgrounds. They may also not employ modals in an effective manner (Hyland, 1994) for graduation of claims such as must versus may. Some students fail to show their attitudes towards their research in the introductions of their essays (Hood, 2004). In addition, published articles have used more interaction with sources than undergraduate student essays (Hyland, 2004). The same was true of low-grade undergraduate freshman essays from both native and non-native speakers of English (Lee, 2010).

\section{Research questions}

The research questions stem from considering the complexities in incorporating an external voice and one's opinion in a coherent, clear text. In addition, the two focal students had considerably different language backgrounds and writing skills, and yet they both struggled with source use. The following questions also seek to understand any differences and similarities in the writing processes and texts of Mara and Wes:

1. How do Mara and Wes engage external voices in terms of incorporation into drafts?

2. How do Mara and Wes' drafts change in terms of source engagement and dialogic voicing?

\section{Methods}

\section{Participants and setting}

The study took place at a large, West-coast, public university in the U.S. Findings are based on a larger research project involving eight multilingual student participants in their final year as undergraduate students. The study looked at the writing development of the students in terms of source incorporation, identity, and language acquisition; 
methods were semi-ethnographic and included classroom observation, student and teacher interviews, and analysis of student writing, and course documents. The class was designed to help students who wanted to be future educators improve their writing, and so readings focused on the primary and secondary public education systems in the U.S.. At the university, all students had to take a final-year writing class, and many types of courses were offered, such as writing for biologists, business students or future educators. The classes were often impacted, so sometimes students found themselves taking whatever course fit their schedule. Nevertheless, Mara expressed a desire to teach and Wes was not sure. Table 1 provides information on Mara and Wes' backgrounds.

Mara had a passion for languages, having spent time abroad in school, for leisure, and for work; she was majoring in Linguistics and hoped to continue on with her academic pursuits to receive a master's degree. Mara transferred from community college, which she had attended off and on over the years and had "chipped away" at course requirements for transferring. Born in the U.S., Mara was raised for a time in a white middle-class community, and after high school attended a small university for less than a year before leaving. Between that time and transferring to the university where this study took place, Mara worked in culinary and patisserie positions and also taught the craft in a trade school. Thus, she could be considered a "mature student," having entered the university system after her 20 s.

Wes was studying archaeology at the university and seemed very interested in the subject, having applied for internships in Washington D.C. and Europe. He was born and raised in Hong Kong and moved to the U.S. when he was 17 years old for college. His father had attended a prestigious U.S. university as an electrical engineer before changing to logistics management. In China, Wes' education was bilingual, with elementary school being Chinese medium with (British) English classes; after elementary school, his education was in English with required Chinese language courses. His

Table 1 Participant background information

\begin{tabular}{lll}
\hline & Mara & Wes \\
\hline Demographic & Female & Male \\
Ethnicity & Hawaiian Chinese & Chinese \\
Age & n/a & 21 \\
Birthplace & U.S. & China \\
Education & & \\
Major & Linguistics & Archaeology \\
EL/ESL designation & No & Yes, in community college \\
Transfer student & Yes & Yes \\
1st in family to attend college & n/a & No \\
Want to attend graduate school & Yes & Yes \\
Want to teach & Yes & Unsure \\
Language & & \\
Spoken with parents & English & Cantonese \\
Studied in school & Spanish, French, Italian & Mandarin, English \\
\hline
\end{tabular}

Though she declined to state her age, I estimate that Mara was between 30 and 35 years of age 
overall outlook on English was utilitarian, in that English served as a means for education and work. He did, however, enjoy reading novels and archaeology related nonfiction books.

When he moved to the U.S., he attended a community college for two years, where he was placed in ESL courses. Wes took a few English writing courses, including a poetry class that he voluntarily enrolled in to improve his English, but that he ended up finding boring due to the teaching style. He discussed difficulties he had when transferring to the university and at times lacked confidence in his (American) English abilities and writing skills. Though enrolled in a course for future educators, Wes expressed little interest in becoming a teacher or working in education; he took the class as a requirement. He decided to enroll in the class due to course scheduling and availability. After graduating, Wes wanted to pursue a PhD in Archaeology.

\section{Writing class and assignments}

The writing course took place during one academic quarter of 10 weeks. Mara and Wes had two different teachers, both of whom were experienced, PhD-holding writing instructors. I observed 9 hours of Mara's teacher, Denise, and over 10 hours of Wes' teacher, Paula. During the observations, I recorded the classroom interactions and took field notes on the activities. The objectives of the observations were to better understand the writing classroom in which my student participants were writing. At the beginning of observations, I introduced myself and invited students to work with me on their writing, since I am an experienced ESL writing instructor. Participation was voluntary and it can be presumed that student interest came from receiving free feedback on their drafts. I met with Wes 4 times and Mara and I met 5 times over the quarter for about one hour per session.

During our sessions, we discussed drafts, instructor feedback, and during one session I interviewed the students about their writing history and experience in school. Mara and Wes chose the topics for their writing, including the main writing project analyzed in this article: a multi-draft research project. For both sections, the main writing project was to research an issue in education and to write an argumentative paper about the issue, using citations and evidence for support. Wes chose to write on the topic of bullying in schools, and wrote a 1377-word paper with 16 citations within the text. Mara wrote a paper that provided an overview of the various theories on language learning and created a 2190-word paper with 26 citations.

\section{Methods and analysis}

Grounded in Bakthinian theory $(1981,1986)$ and Systemic Functional Linguistics (SFL) (Halliday, 1994), which sees language as fundamentally dialogic, the Appraisal framework serves as an approach to analyze oral and written discourse with the intent of understanding how speakers evaluate ideas, express stance towards individual, and overall interact with the world and the people within it. Like SFL, the theory has a variety of classification systems and inter-related levels of analyses that range in complexity. It is possible to incorporate just a few or all of the taxonomies. Appraisal has foundational texts (Martin \& Rose, 2003; Martin \& White, 2005) but is still in development, its extensive website on the theory most recently updated in 2015 on the Appraisal Website 
("The Appraisal Website," 2015). Because of this, the classification system has been understood in slightly varying ways when it comes to detailed taxonomies.

However, Appraisal has three main branches for analyzing discourse which are interrelated: Attitude, Engagement, Graduation (Martin \& White, 2005). Attitude pertains to "feelings, including emotional reactions, judgements of behavior and evaluation of things" (Martin \& White, 2005, p. 35). Engagement looks at "sourcing attitudes and the play of voices around opinions in discourse" (p. 35). Graduation addresses "amplification" of attitude and "grading phenomena" (p. 35). The branch used to answer my research question and analyze my data is engagement, which looks at how individuals express their attitudes and ideas through various linguistic forms. More specifically, engagement involves the interaction of voices and response in a text. In terms of undergraduate essay writing, engagement could be used to analyze how a student frames and discusses an external voice. Since Appraisal is based on Bakhtinian theory of dialogism, a student's text can be analyzed in terms of the multiple voices and opinions discussed in a text. It should be noted that the three branches of Appraisal interact in a text, and that the interplay of voices in a text necessarily involves evaluation, the expression of Attitude. One goal of Appraisal is to address these crossovers ("Engagement," 2015). My use of the term evaluation refers to any type of language that demonstrates an assessment of an external voice, without necessarily approaching the branch of Attitude, since it is beyond the scope of this study to do so.

Student texts were analyzed using the open-source language coding and analysis software, the UAM Corpus Tool with the Appraisal framework template for codes. I adapted the systems (Martin \& White, 2005; "The Appraisal Website," 2015) for my study and drew upon Hu and Wang's (2014) coding system which also bases itself on Appraisal. During the coding process, I identified any explicit citation found in all drafts of the focal participants' research texts. I then analyzed the text according to my adapted categorization system. After the coding, I looked for patterns within and across participants and drafts. I identified some reoccurring collocations of coded features, specifically those related to in/end of text citation and type of incorporation; I also noted whether the external voice was the subject, agent, or topic of a main clause. I then considered holistically how these features contributed to a text that was dialogically contractive or expansive, and what the data meant for the use of Appraisal in student writing. Such analyses were then considered in light of data from interviews, artifacts, and classroom observations. In this way, I could explore connections between the linguistic features of the texts and student background while also triangulating data and cross-checking as needed. It is also important to note that my analysis did not address intentionality of the student writers or try to explain what they were "thinking" when writing the text. Rather, I analyzed stance in the framework of the student as an actor in a social practice of writing argumentative text using research. The student was "operating to reflect the process of interaction or negotiation within a text between alternative socio-semiotic positions" (“Engagement- a Bakhtinian perspective," 2015, para. 9).

\section{Text classification typology using engagement}

Considering all utterances as dialogic and responding to some degree to a previous utterance, the term dialogic must be further categorized for linguistic analyses. 
Engagement discusses two broad categories, contrasting dialogistic diversity and expanding dialogistic diversity ("Dialogistic expansion and contraction," 2015). The sub-categorizations for these two polarized ends have changed in recent years within Appraisal (Martin \& White 2005 vs "The Appraisal Website" 2015). For example, the most recent subcategorization on the Appraisal Website; for contracting voices, there are six subcategories for dialogic contraction: disclaim:denial, disclaim:counter-expect, proclaim:expect, proclaim:pronounce and extra-vocalise:authorially-endorsed. For expanding voices there are four subcategories, probabilise:evidence, probabilise:likelihood, probabilistic:hearsay and extra-vocalise:endorsement neutral. For the focal students' texts, I adapted four categories for analyzing text dialogue and provide my own descriptions and examples, as seen in Table 2.

I did this because I found collapsing the categories to be more effective for analysis and for the specific student texts, but they are very much grounded in Appraisal (Martin \& White 2005 vs “The Appraisal Website" 2015). The ten subcategories discussed above and the four I adapted for this paper serve to further understand the nuances of dialogism and dialogic expansion or contraction. In theory, depending on the genre of discourse, certain categories may be present more than others. For example, in the student essays, I did not see much "disclaim:counter-expect" or "probabilise:hearsay." However, these types of dialogism might be present in a political opinion text in a newspaper, for example. I categorized texts into these four categories based on linguistic features like the modals can or could which signal possibility versus the conclusive future tense will. I also looked at the type of reporting verb used, the subject, and the connecting words like however, thus, and despite.

Beyond dialogic expansion and contraction, I analyzed the incorporation of external voices (outside sources): textual integration, author integration, vocalization and endorsement, as seen in Table 3. The first two are often addressed in research on academic writing and the latter two are fully addressed in discussion of Engagement in Appraisal. Analyzing the writing with these four additional categories allows for an indepth understanding of external voice use, beyond dialogic expansion or contraction. For example, author integration allows to see whether the external voice is recognized in the text beyond a citation, which may influence the dialogue. In addition, endorsement allows to address the question of evaluation to understand whether or not the student writer promotes the idea(s) of the authorial voice. While coding, linguistic cues such as modality (modals, adverbs), sentence structure and subjects, and reporting verbs were accounted for.

Table 2 Analyzing external voices with engagement: four categories of dialogic voicing

\begin{tabular}{|c|c|c|c|}
\hline Engagement & Term & Description & Example \\
\hline \multirow{3}{*}{$\begin{array}{l}\text { dialogic } \\
\text { contraction }\end{array}$} & \multirow[t]{2}{*}{ pronouncement } & \multirow{2}{*}{$\begin{array}{l}\text { closes down a dialogue; can be a bare } \\
\text { assertion that looks like facts. }\end{array}$} & - This is really the case. \\
\hline & & & - It is true that... \\
\hline & $\begin{array}{l}\text { disclaim or } \\
\text { deny }\end{array}$ & narrows down the possible answers & $\begin{array}{l}\text { - They believe this but the study } \\
\text { shows that they are wrong. }\end{array}$ \\
\hline \multirow{4}{*}{$\begin{array}{l}\text { dialogic } \\
\text { expansion }\end{array}$} & \multirow{2}{*}{$\begin{array}{l}\text { entertain and } \\
\text { highlight }\end{array}$} & \multirow{2}{*}{$\begin{array}{l}\text { recognizes other possible truths and } \\
\text { uncertainties }\end{array}$} & - That is an option. \\
\hline & & & - They must look at this. \\
\hline & \multirow{2}{*}{$\begin{array}{l}\text { possibility or } \\
\text { probability }\end{array}$} & \multirow{2}{*}{$\begin{array}{l}\text { recognizes other points of view; the } \\
\text { chances of a statement being true }\end{array}$} & - Other people might think... \\
\hline & & & - It is most likely true. \\
\hline
\end{tabular}


Table 3 Other categories for analyzing external voices

\begin{tabular}{|c|c|c|c|}
\hline Category & Question addressed & Possible answers & Examples \\
\hline \multirow{3}{*}{$\begin{array}{l}\text { textual } \\
\text { integration }\end{array}$} & \multirow[t]{3}{*}{ How is the text incorporated? } & - Quotation & - Smith(1999) says, "this is..." \\
\hline & & - paraphrase & - Smith (1999) states... \\
\hline & & $\begin{array}{l}\text { - quotation and } \\
\text { paraphrase }\end{array}$ & $\begin{array}{l}\text { - Smith (1999) states ... and } \\
\text { that people "should..." }\end{array}$ \\
\hline \multirow{2}{*}{$\begin{array}{l}\text { author } \\
\text { integration }\end{array}$} & \multirow[t]{2}{*}{ Is the external voice mentioned in the text? } & - yes (integrated) & - Smith (1999) states... \\
\hline & & $\begin{array}{l}\text { - no, end of text } \\
\text { citation only }\end{array}$ & $\begin{array}{l}\text { - It is known that... (Smith, } \\
\text { 1999). }\end{array}$ \\
\hline \multirow[t]{4}{*}{ vocalization } & \multirow{4}{*}{$\begin{array}{l}\text { Who/what is the subject/agent of the } \\
\text { sentence? Whose voice is present? }\end{array}$} & - external voice & - Smith (1999) states... \\
\hline & & - authorial voice & - I believe... \\
\hline & & $\begin{array}{l}\text { - abstract / } \\
\text { inanimate object }\end{array}$ & $\begin{array}{l}\text { - The reality is... It is } \\
\text { important }\end{array}$ \\
\hline & & $\begin{array}{l}\text { - animate object / } \\
\text { passive voice }\end{array}$ & $\begin{array}{l}\text { - Research shows... It is } \\
\text { known... }\end{array}$ \\
\hline \multirow[t]{2}{*}{ endorsement } & \multirow[t]{2}{*}{$\begin{array}{l}\text { Does the student endorse the external } \\
\text { voice's ideas? }\end{array}$} & - yes (endorsed) & $\begin{array}{l}\text { - Smith (1999) effectively } \\
\text { shows... }\end{array}$ \\
\hline & & - no & $\begin{array}{l}\text { - Smith (1999) claims to } \\
\text { know... }\end{array}$ \\
\hline
\end{tabular}

The first two categories of integration are fairly straightforward. For textual integration, I coded sentences that mentioned an external voice in the text or at the end of a text. I categorized these cited sentences as either quoted or paraphrased. Second, author integration is whether or not the external voice was mentioned by name within a text, such as Smith (1999) says or According to Smith (1999). This was first discussed extensively by Swales (1990). I at times refer to this as "in text citation" or "in text referencing" of an external voice within a text. End of text citation means the only indication of the external voice is in the parenthetical citation at the end of a sentence, such as ...(Smith, 1990, p. 2).

For the third and fourth categories, I chose to address them separately rather than have them as part of the ten subcategories of dialogism discussed on the Appraisal Website ("Dialogic expansion and contraction," 2015). I did this because they have different qualities than the other categories, such as "probability" and are interesting enough to look at individually. In addition, for teaching purposes, it is useful to address vocalization and endorsement as different if linked to dialogic voicing. For the third category, vocalization, while $\mathrm{Hu}$ and Wang (2014) limited their analysis of external voice to integration, described above, there is another way to view sources, vocalization, which more specifically addresses the type of author integration where the external voice is not mentioned, because it further categorizes agents and subjects ("The Appraisal Website" 2015). The two ends on this scale are extra- and intra-vocalization: Extra-vocalization is when an external voice is explicitly integrated, such as Smith (1999) states...whereas intra-vocalization occurs when there is reference to the authorial voice, such as I believe. In between are types of vocalizations where there is an abstract agent and non-animate subjects, such as research shows; some cited sentences are in passive form such as it has been shown. Classification such as this helps to elaborate on what types of subjects or agents are being used in sources with non-integrated external voices.

The last way to analyze the use of an external voice is endorsement, which is part of a classification system about writer stance addressed by $\mathrm{Hu}$ and Wang (2014). It basically 
looks at what kind of stance the authorial voice, in this case the student writer, takes towards the external voice. Just as there is stance for an argument, so too is there a type of stance towards a person. Endorsement is often discerned with reporting verbs and phrases, as well as surrounding texts. Student writers may use a source in order to support their own arguments, in which case they would endorse the propositions of an external voice, as seen in Table 3. Hu and Wang (2014) identifed other types of writer stance, such as acknowledging the ideas of an external voice, such as the government released a statement or Smith (1999) says. However, after analyses, I found my students were mostly endorsing their sources and so I mostly consider writer stance in terms of endorsing the external voice.

Although texts that endorse external voices could be considered dialogically expansive, in that the external voice was mentioned in the text, creating a dialogue of sorts, I considered them to be contractive given that the student writer closed down the possibility for the reader to contest the argument, as described by Martin and White (2005):

Endorsements act to construe a heteroglossic backdrop of potential alternative viewpoints for the proposition. However, simultaneously, the endorsement functions to exclude any such alternatives from the ongoing colloquy... (p. 127, italics added).

Table 4 provides two example sentences and how they would be categorized across all five types of analyses. Wes' paraphrased sentence is dialogically contractive, having no mention of an external voice. Wes implicitly endorses the external voice because the sentence serves as a bare assertion of facts and he does not indicate his opposition to such a claim. Mara's sentence is a paraphrase that takes a more neutral approach and acknowledges the external voice more than endorsing it. Acknowledging an idea indicates that the sentence is dialogically expansive since it entertains other people's arguments.

\section{Results}

Considering the four categories of source incorporation, textual integration, author integration, dialogic expansion/contraction, and endorsement, Wes and Mara's writing varied. First, Wes' research article contained only paraphrases and while Mara's also contained mostly paraphrases, she did include some quotations. When Mara used an external voice, she often included the external voice in the sentence, whether paraphrased or quoted. Wes sometimes included the external voice at my encouragement. While Mara's texts tended to be dialogically expansive with citation use, Wes' tended to

Table 4 Two examples of analyzing external voices with the five categories

\begin{tabular}{|c|c|c|c|c|c|}
\hline Student text & Dialogism & $\begin{array}{l}\text { Textual } \\
\text { integration }\end{array}$ & $\begin{array}{l}\text { Author } \\
\text { integr- } \\
\text { ation }\end{array}$ & $\begin{array}{l}\text { Vocaliza- } \\
\text { tion }\end{array}$ & $\begin{array}{l}\text { Endor- } \\
\text { sement }\end{array}$ \\
\hline $\begin{array}{l}\text { Kids that are more likely to become bullies } \\
\text { are often possessive, aggressive or have low } \\
\text { self-esteem (stopbullying.gov). [Wes] }\end{array}$ & $\begin{array}{l}\text { dialogic } \\
\text { contraction: } \\
\text { pronounce or } \\
\text { proclaim }\end{array}$ & paraphrase & no & $\begin{array}{l}\text { passive } \\
\text { voice, } \\
\text { unknown } \\
\text { agent }\end{array}$ & yes \\
\hline $\begin{array}{l}\text { Kumaravadivelu (2006:165) suggests a } \\
\text { movement toward recognizing... [Mara] }\end{array}$ & $\begin{array}{l}\text { dialogic } \\
\text { expansion: } \\
\text { entertains }\end{array}$ & paraphrase & yes & $\begin{array}{l}\text { external } \\
\text { voice }\end{array}$ & no \\
\hline
\end{tabular}


be dialogically contractive. I will discuss these aspects of engagement and dialogism in analyzing the students' writing drafts. Analysis of Wes and Mara's drafts reveal changes in dialogism, argumentation, textual integration, author integration, and external voice endorsement. I will consider them separately before comparing them.

\section{Wes: Appealing to sources, creating dialogue and engagement}

Textual and authorial integration factor into the expression of student opinions in their writing, a phenomenon often referred to as voice. A student's voice can be "lost" when incorporating outside sources and when speaking of an external voice "taking over" a text, it is typically said that quotations do this. If too many quotations are used, then the authorial voice disappears. However, it is not just the feature of quotation marks that can make a student's writing appear voiceless. There are linguistic features whose presence (or absence) affects voice.

This was the case with Wes, whose research paper went from relatively voiceless and monologic to more dynamic and dialogic. His drafting process dealt with issues of voice, paraphrasing, and integration of the external voice. It is a demonstration not only of changes in writing but also the role dialogism may play in establishing voice. Wes' final paper on bullying and how to prevent it had textual integration that was entirely paraphrased. The changes made in the draft pertain to authorial integration and stance, and two drafts of one particular paragraph are shown in Table 5. When Wes and I met to go over his rough draft, we discussed the feedback he received from his instructor, Paula, who had written in the margins, "You seem to be relying on this one website for solutions about identification. Where is your voice here?" (Instructor feedback draft 1). When I asked Wes what Paula meant by this, he stated that he did not put his own

Table 5 Comparison of a section of Wes' rough and final draft

\begin{tabular}{|c|c|}
\hline Rough draft: Ambiguous endorsement, bare assertions & Final draft: Dialogic voicing, endorsement cues \\
\hline $\begin{array}{l}\text { To identify bullying early, one of the better ways to do } \\
\text { it is to identify who is at risk of bullying others or } \\
\text { being bullied. Children who have a higher chance to } \\
\text { be picked on including those with low self-esteem, } \\
\text { less popular among peers or consider 'different' } \\
\text { among their peers such as overweight (stopbullying.- } \\
\text { gov). Kids that are more likely to become bullies are } \\
\text { often possessive, aggressive or have low self-esteem } \\
\text { (stopbullying.gov). Other ways to spot bullying is to } \\
\text { pay attention to warning signs that show possible } \\
\text { bullying (stopbullying.gov). Children with unex- } \\
\text { plained injuries, damaged personal properties or de- } \\
\text { clining grades are good signs that hint they are } \\
\text { targeted (stopbullying.gov). Kids with unexplained } \\
\text { extra properties or are increasingly aggressive are } \\
\text { signs that show kids are bullying others (stopbul- } \\
\text { lying.gov). With some of the above tips, teachers are } \\
\text { more capable to detect any bullying. }\end{array}$ & $\begin{array}{l}\text { To identify bullying early, one of the better ways to do } \\
\text { it is to identify who is at risk of bullying others or } \\
\text { being bullied. According to stopbullying.gov, } \\
\text { children who are more likely to become bullies or } \\
\text { victims usually possess some characteristics. Children } \\
\text { who have a higher chance to be picked on including } \\
\text { those with low self-esteem, less popular among peers } \\
\text { or consider 'different' among their peers such as over- } \\
\text { weight. ' Kids that are more likely to become bullies } \\
\text { are often possessive, aggressive or have low self- } \\
\text { esteem (stopbullying.gov).Another way to spot } \\
\text { bullying is to pay attention to warning signs that } \\
\text { show possible bullying as suggested in stopbul- } \\
\text { lying.gov. Children with unexplained injuries, dam- } \\
\text { aged personal properties or declining grades are good } \\
\text { signs that hint they are targeted.' Kids with unex- } \\
\text { plained extra properties or are increasingly aggressive } \\
\text { are signs that show kids are bullying others (stopbul- } \\
\text { lying.gov). With some of the above tips, teachers are } \\
\text { more capable to detect any bullying. Moreover, schools } \\
\text { should encourage parents to follow the above tips to } \\
\text { pay closer attention to their children. If there are any } \\
\text { possible signs that the parents noticed which are over- } \\
\text { looked by the teachers, parents should contact schools } \\
\text { for help. }\end{array}$ \\
\hline
\end{tabular}


opinion and relied too much on the author (Interview, 11/3/12). Closer analysis of the draft reveals what his instructor might have meant with "voice" and lack of opinion.

In the rough draft, it can be seen that nearly every sentence ends with a citation of stopbullying.gov; the sentences tend to be dialogically contractive in that they make bare assertions/pronouncements, functioning to give neutral, established definitions. The complement sentence structure of the propositions creates a stative, established stance. There is no integration of the external voice or intra-vocalization, which creates a dialogically contractive paragraph whose main "speaker" is the external voice, as noted by Paula. The repetition of end of text citations may also suggest that the voice comes more from the external voice than Wes.

Wes ended up revising this paragraph for the final draft in several ways, including integration of the external voice, which created a more dialogically expansive paragraph. Furthermore, the appeal to authority with the attributed according to and as suggested in indicates Wes' endorsement of the propositions being made by the government website for bullying, which can be reasonably considered an authority on the subject. With these changes, the dialogue becomes more explicit as well as an establishment of voices and evaluation. In respect to his opinion, at the end of the paragraph Wes added an explicit assessment of the propositions made, saying that involved parties should take particular actions. As to why these changes in his text might have occurred, Wes and I discussed the instructor's feedback and how to go about making changes. We discussed mentioning the source within the sentence and I suggested the phrase people/advocates at stopbullying.gov. Regarding end of text citations, I told him that he did not have to put a citation after every sentence. When asked about where he was going to put his opinion, Wes said he was going to put it after the discussion of the source. In addition, I reminded Wes that Paula had noted in class not to use I think or I believe since it added to "wordiness"(Interview, 10/24/12), and asked how he was going to show which sentences were his opinion. Wes said he would use the modal should, which appeared in the final draft. Wes recognized his voice was lacking in the rough draft, but he also expressed uncertainty over citing sources as well as generating his own ideas or stances on other's ideas. Later, in a writing response assignment, Wes noted that his lack of knowledge on the topic and lack of skill with citation practices prevented him from including his voice in an effective way:

"I have a hard time adding some of my own comment in the paper as mentioned in my rough draft because I am unfamiliar with the topic. Also, in that particular paragraph that lacks my own opinion, I was not sure how I was going to remove some of the in-text citations because [Researcher] said that those citations made that I was summarizing others' opinions as my opinion. However, I was very reluctant to trim remove [sic] those citations because I was not sure whether it was a good idea to risk not giving credits to my sources. I tried to add more details to the reference part because Researcher said that I need to introduce my sources in a more detailed way." (Reflection Assignment, italics added)

Despite these uncertainties and the attribution of source introduction as "detailed," Wes made changes in his final draft that created a dialogue between himself and the external voice as well as a clearer reference to his own beliefs. 
For the instructor Paula, the students' voices were central to the research paper, which she described as an "academic conversation," noting that what they were doing is "reading what's been said and you're entering the conversation and putting your stamp on it. Your point of view...your opinion is a reasoned one, an educated one..." (Observation, 1/31/13). While it is not clear what the instructor thought of Wes' revised draft, I argue that the integration of the external voice helped create a "conversation" and Wes' inclusion of his suggestions at the end of the paragraph was congruent with "putting your stamp on it." Despite being a paraphrase, his rough draft lacked dialogic voicing and stance with the lack of integration of external voice and bare assertions, which also created contractive voicing. Even though the external voice and Wes had the same argument, which may contract the dialogue, the use of another's voice and modality (should) opened up the conversation for the reader to consider the propositions rather being forced to concur with them.

The changes made in Wes' draft came out of his need to establish his opinion while also discussing information from an external voice. For him this was challenging because he did not have a strong background on the topic and he also was uncertain about citation rules and ways to avoid transgressive source use while paraphrasing. He struggled with distinguishing himself from others linguistically. What seemed to give him more of a voice was actually recognizing the voice of another, with his addition of attributive phrases such as according to and as suggested by. With the integration of the external voice, the information from the stopbullying.gov website changed from being factual and monologic to being arguments from a government body, which Wes was relaying to his audience. In evaluation theory (Martin \& Rose, 2003), according to has been considered a neutral assessment of attribution. However, Wes appeared to be using this phrase as a way to introduce the ideas of an authoritative external voice to strengthen his argument. In other parts of his essay, he uses this phrase to introduce an argument that given the argument of his essay, is fully endorsed by Wes:

(1)According to a guide issued by the U.S Department of Justice, the commitment of the school principals is a vital part in countering bullying in school (U.S

Department of Justice 2002). [Wes]

(2) According to the U.S. Department of Education, 160,000 children avoid school per day because they are afraid of bullies (Dubreuil and McNiff, 2010). [Wes]

A question remains of whether the frequent use of according to, though dialogic, indicates a limited linguistic repertoire for discussing a source or an over-reliance on pleading to authority for legitimacy in argumentation. I would describe Wes as not a very confident writer. Perhaps students' perceptions of their own abilities in writing affects how they seek to use sources, in this case relying on authoritative discourse. Furthermore, rather than using an abstract subject/topic or presenting the cited information as authorless, the integration of external voice within a text somewhat opens up the dialogic backdrop in which the argument takes place. The student writer demonstrates to the reader the conversation occurring with the cited source; it is one that looks to the external voice as a legitimate generator of facts and ideas worth mentioning in their argument. It also situates the argument and knowledge in a socially 
embedded practice, whose speakers come from various disciplines, viewpoints and authoritative backgrounds (Bakhtin, 1981).

Wes was also able to show his endorsement of the website while including his own opinion, which he identified as his own by placing it after the block of sentences that discussed the external voice's opinion. He used the modal should to indicate his ideas for the reader to take action. The factors dealt within this paragraph revision, textual integration, authorial integration, and expression of stance were a part of every interaction with a source for Wes.

\section{Mara: Negotiating author integration and identifying one's opinions}

Mara had a similar experience as Wes during the drafting process when it came to distinguishing voice and opinion during source integration. Also, her rough draft lacked in-text citation of external voices, and the source texts were integrated via paraphrasing. Unlike Wes, Mara had clear arguments on the topic she was writing about. The changes in her final draft reveal ways in which Mara creates and then joins in on a dialogue with the external voices by changing the ways in which the external voices are integrated into the text. Specifically, Mara uses linguistic moves including quotations to identify the boundaries of voices, including her own. The changes made in the final draft also demonstrate the ways in which she endorses the external voices and uses them to support her own ideas in an appeal to authority. Discussions with Mara on these changes reveal a mixture of her struggle both with distinguishing her voice and ideas from the external voices and also conforming to standard academic writing practices.

As a step in the research project for the course, for one assignment Mara wrote a short research-based text on what instructors should know about second language acquisition theory and research. Table 6 shows an entire paragraph in two versions: a rough draft and a final draft. In this paragraph, Mara is trying to discuss her own opinion as well as those from experts in the field. In the rough draft, the latter half of the paragraph contains two paraphrased sentence with end of text citations, which offer opinions of what is or what can be for teachers and language theory. However, in the final draft, Mara inserts the external voice's names into the text and by reporting their ideas, displays her endorsement for them. Specifically, the external voice Mary Borba became the subject and agent of a sentence with Mary Borba concurs that... The reference to which Borba concurs is the proposition Mara makes in the previous sentence. The paraphrased, end-of-text citation of Borba changes into a dialogic sentence serving to support Mara's arguments.

The final draft expands on Borba's arguments by including a quote that gives the rationale for supporting such an opinion, starting with She states that... Mara creates a dialogically expansive space by using a relatively neutral reporting verb, states. At the same time, the way in which Mara discusses the second external voice in the final draft creates a sense of dialogic contraction by appealing to authority to support her claims. In the rough draft, Mara discusses a possibility about teacher education by paraphrasing and citing Jim Cummins, but not mentioning him in the text. Like Borba, in the final draft Cummins is incorporated into the sentence and becomes a subject and agent starting with the sentence Cummins argues that... Mara also changes from only paraphrasing to also quoting Cummins. 
Table 6 Comparison of a section of Mara's rough and final draft

Rough Draft: neutral evaluation and little source integration

My experience in light of Pettis' words causes me to critically evaluate the how language is formally taught within schools. The ways in which second- and foreign languages are taught should matter, not only to educators, but also to learners and to our society. For educators, this means having enough training or background so that they can summon diverse teaching methods in the classroom to pre-empt statements such as the ones reported by Pettis. The benefits of this are twofold. Teachers receive adequate training and students receive appropriate instruction. Then, when educators can implement the most appropriate methods and processes by which to teach language, they can appropriately build upon students learning while being mindful of their diverse needs (Borba, 2009). Furthermore, teachers who feel as if they have sufficient preparation are, in general, better equipped to lead a classroom. Specifically, teachers who are better equipped can then promote and accelerate students' development (Cummins, 2003)
Final Draft: Stronger evaluation and source integration

Reflecting upon my experience in light of Pettis' words causes me to critically evaluate how language is formally taught within schools. In my opinion, the ways in which second- and foreign languages are taught should matter, not only to educators, but also to learners and to our society. For educators, this means having enough training or background so that they can summon diverse teaching methods in the classroom in order to pre-empt statements such as the ones reported by Pettis. The benefits of this are twofold: teachers would receive adequate training, and students would gain varied methods of instruction. Mary Borba concurs that educators could then implement the most appropriate methods and processes by which to teach language so as to build upon students' learning. She states that when teachers understand the processes of language development, "their expectations are more realistic, and they are able to scaffold learning appropriately" (2009:374). I agree with Borba, and so does Jim Cummins. Cummins argues that teachers can further promote and accelerate students' development by implementing pedagogical approaches that "succeed in liberating students from instructional dependence," (2003:32).

Importantly, in between discussion of the two external voices, Mara adds a sentence that explicitly draws the reader's attention to her own beliefs as related to the external voices. She states I agree with Borba, and so does Jim Cummins. This sentence serves a few rhetorical functions. For one, it adds to the ways in which Mara identifies herself in the research paper, including changes in the beginning part of the paragraph that highlight her ideas, such as In my opinion, as well as the evaluative quality of some of the reporting verbs. In addition, Mara makes it clear that she endorses the arguments of the external voices and that they in some ways also endorse hers. Mara appeals to authority to create a strong if dialogically contractive argument for her reader by adding she not only agrees with Borba but also a well-known researcher, Jim Cummins.

As for motivations behind these changes, I discussed this passage with Mara after noticing the change in textual integration, from paraphrasing to quoting. I asked her why she made such changes in this paragraph, and we had the following conversation:

Miki: Do you think quoting is better than paraphrasing them? I see you quote Borba and quote Cummins and this one you paraphrase.

Mara: Let me see it. I think 'cus this is more like. This is what they said but this is me making connections between what I think their quotes... And here I'm summarizing why the connections are important. 'Cus the whole thing. This is me. I'm making this statement. And my opinion, 'this is a win-win here's why because teachers'. This was a stretch...

Miki: And this is because you thought that you needed to do this for the paper? To include your personal opinion? 
Mara: Yes. It was a bizarre assignment and I probably took it down a difficult and wrong path. And then I got into Cummins and it was like yeah here's someone else who shares my ideas but it's slightly different 'cus he's criticizing traditional education approaches. (Interview, 11/21/12)

Mara's response reveals her focus on creating a cohesive text in which all the participating voices are in dialogue with one another rather than separate entities; she describes this when talking about "making connections" and "summarizing why the connections are important." Most importantly, Mara is trying to show the reader that the ideas and some of the language are hers first and foremost, when she says, "Cus the whole thing. This is me. I'm making this statement." During the research process of reading over previous work, Mara found an author who shared her opinions, Jim Cummins, which she demonstrates when stating, "Here's someone else who shares my ideas." Based on these comments, it seems apparent that Mara was aware of the dialogic nature of source use as well as some rhetorical functions of them in academic writing.

However, like Wes, Mara was notably unsure about how to incorporate her own ideas when discussing outside research when explaining that she took the assignment "down a difficult and wrong path." She discussed this uncertainty later in the conversation when discussing how to integrate information. She said:

“...I struggled with this because I didn't know how to tie things into sources and additionally, umm, personal experience. So I had to say what's my experience. How- How do I make a statement about my experience and why I think it's important that we look at our methods? 'Oh well we want our methods to be strong for these reasons' ... I wrote it because I struggled. But this was-This- I integrated the "I agree with and so does Cummins." That was the last- the final draft. Because I was like How do I make it stronger? How do I make my point stronger? Oh, I'll throw this in." (Interview, 11/21/12)

In this excerpt, Mara describes her solutions to integrating her own voice in her argumentative text while trying to demonstrate to the reader the legitimacy of her arguments. Her final draft changed not only the way she integrated the text (paraphrase to quoting) but also the author (from no mention of the external voice to integration). These changes reflect decisions made by Mara which relate to her drive to make a compelling argument for her audience by using external voices while maintaining a boundary between voices.

In addition, despite her misgivings, Mara incorporated sources in a fairly sophisticated manner. For example, in the paragraph below, she was able to orchestrate a dialogue (Bakhtin, 1981) between three theorists, paraphrasing their opinions with fairly neutral verbs suggests and advocates, such that the audience can read and judge the ideas on their own, which $\mathrm{Hu}$ and Wang (2014) describe as an employment of "attitude-free" verbs (p. 21).

Kumaravadivelu (2006:165) suggests a movement toward recognizing and implementing alternative strategies that maximize learning opportunities, promote the learner's autonomy, and foster language awareness [1]. Principles that underlie classroom activities, suggests Brown (1997:12), should be woven into approaches 
and pedagogy to bolster strategies so that students can benefit from meaning learning, develop motivation, and gain self-confidence in their learning and in their L2 [2]. On the other hand, a competent teacher will also compensate for limitations of methods by evaluating and developing her own effectiveness as an instructor [3]. This is congruent to how Pettis (1997:394) advocates that teachers uphold a commitment to professional development and periodically assess their own knowledge and skillset of the field of L2 teaching [4]. Teachers, who then make themselves and their methodologies available to regular observation and critique, are in a better position to identify and adapt new strategies and techniques (Horowitz, 2008:224) [5].

Additionally, it is imperative that good teachers continually improve, or at least maintain, their own knowledge of the L2 or foreign language so as to not become restricted by any language limitations that could influence their presentation of or reliance upon certain features of methods [6]. [Mara]

Nevertheless, Mara does include her opinion, such as in sentence [4], which supports her proposition introduced in sentence [3]. Joining the dialogue, Mara makes a claim and has Pettis concur with her. A final evaluation is made in the last sentence [6], in which a pronouncement about a need is made, without a reference to an external voice. What this example shows is that student writers can use a variety of external voices and have relatively neutral stances towards them while weaving in their own arguments. Indeed, discourse and the student texts are filled with opinions towards propositions and other people, such that a single utterance can be filled with multiple voices with varying points of view. What this example also demonstrates is the rather sophisticated text Mara created by creating such a dialogue with varying sentence structure and ways of incorporating the external voices. Again, given that Mara was a fairly confident writer and wrote with a command of academic language, achieving such a dialogic paragraph may be considerably easier for her to do than the participants who struggled with academic language.

\section{Discussion}

As discussed in the Introduction, this article had two goals: to analyze student engagement with external voices and to discuss how teachers might use Appraisal and engagement during writing instruction. Linked to these goals are two research questions which were addressed using case study methods. As a reminder, the questions were how Mara and Wes engaged external voices and how their drafts changed in terms of engagement. I summarize below the answers to the two questions. In general, while different in various ways, including general linguistic and academic writing skills, Mara and Wes proceeded through drafting processes with source use in similar ways. Both revised their drafts so that there was source author integration and other explicit reference to external voices. Although Mara held a stronger opinion on her writing topic, both Wes and Mara made changes so that their own voices could be more clearly distinguished. For Wes, this was done by placing his opinion at the end of the paragraph and changing the use of verbs from factual statements to propositions through the modal should. Mara added in explicit references through self-referential pronouns and stating her own opinions, such as I agree. With these changes, the student writers engaged in a dialogue with their sources while continuing to endorse and use them to 
advance the overall argument. However, while Wes worked out how to create a dialogic text through discussion with me and considering the instructor's feedback, Mara went through this process on her own, which may reflect her more advanced academic literacy skills.

The students were working to orchestrate various voices in their argumentative texts, including the external voices, and their own points of view on educational issues. The source was used to confirm the students' arguments by appealing to authority and evidence. Students also varied in whether they mentioned the external voice within the text or not; when integrating the external voice, Wes appealed to authority of the sources by frequently using the phrase according to, appealing to authority. The use of external voices made such student texts dialogic, but the extent to which the dialogue allowed for multiple voices varied, such that there is a range of expansion and contraction; students engaged the external voices in various ways.

In addition, the use of these different features may interact with how a student's own opinions are demonstrated, as well as the overall strength of the text. For Wes, considerations of integration, stance, and end of text citation changed his paragraph from a dialogically contractive one to a conversation filled with various opinions, which seemed to be what his instructor was looking for in the student papers. So rather than just looking at the interaction of the authorial voice and reader (Hyland, 2005), considering the interaction with the external voice appeared to help Wes improve his writing. Mara also engaged in struggles with dialogic voicing and external voice use, revealing the importance at times in argumentative writing of identifying voices of external voices and the self when writing.

Besides quotations, some paraphrases showed ambiguity of stance and ownership when they did not integrate the external voices; in this case, there was a lack of a clear voice since the vocalization was an non-human subject, as in it or studies. When Wes had a paragraph where nearly every sentence was like this, the overall effect was that the voice belonged to the external voice. After receiving Paula's feedback regarding over-reliance on one source and lack of voice and opinion, Wes was able to make changes in his final draft by integrating the external voice into cited sentences, thus creating a more dialogic text. Moreover, Wes was aware of his lack of voice in his writing, but it is not clear if his perceived and real academic skills influenced such writing. Although he was mostly proficient in his language skills, Wes thought his language might be "awkward" for his American peers. He mentioned this when we discussed peer feedback on a printed rough draft, where his peers had crossed out some phrases, replacing them with their own words. Mara also struggled with identifying her voice when discussing external voices, despite her relatively high English language proficiencies and academic literacy. Mara revised her drafts in such a way to make her own voice clearer as well as her attitude towards the external voice. What Mara and Wes' experiences demonstrate are the challenges that students in general face when negotiating voices within an academic text.

To address the second goal, I will now discuss how instructors may use Engagement from the Appraisal framework to help students learn to incorporate external voices in their writing. To start, this is a question that deserves research in its own right and voices of writing instructors who have experimented with bringing the Appraisal framework, specifically engagement, into their lessons. One initial benefit for using 
engagement with students stems from its categorization and hierarchies of language, which provide the clarity and structure students need. At the same time, as this paper demonstrates, these categories are not rigid but adjustable, which means bottom-up adaptations can be made by teachers depending on the writing tasks. For example, just as I found little Hearsay in my student writing, so too might instructors adapt the framework. Incorporating external voices remains an important part of academic writing, yet students often only receive a lesson on plagiarism and the three forms of source incorporation (paraphrase, quotation and summary). More is needed for effective source use. Because of its grounding in Bakhtinian theory of dialogism, Appraisal offers an alternative perspective on academic writing for students: it is a conversation among voices, one of which is, very importantly, the student's voice.

The practices of conversation are much clearer to students than the practices of academic writing and external voice use, such that understanding writing in this way may facilitate student writing processes. For example, arguments involve taking a stance, denying, proclaiming, and entertaining, all of which are categories of analysis in Appraisal. Instructors can use Appraisal to teach the language of stance and engagement in English through verb choice, modal use, extra-vocalization, subject choice, etc. In my experience as a teacher, verbs or phrases to incorporate external voices are often provided without distinction of the stance or dialogic voicing implied, such as the difference between Smith shows, Smith argues and Smith proves. One classroom activity could include discussion of stance and engagement with Appraisal followed by categorization of verbs and phrases used for discussing external voices according to dialogic voicing and evaluation. After, they could practice writing out phrases in which they experiment with different types of engagement of an external voice, such as pronouncing the external voice's ideas versus entertaining the ideas. These sentences would then be discussed with the teacher and the rest of the students in terms of their effective use of language and the overall dialogic voicing created, and its appropriateness for the writing task. Finally, instructors could even compare the drafts of Wes and Mara with their students and discuss the linguistic changes and how that affected the dialogue with the external voices. The case study of these two students can also show student writers that engaging external voices remains a challenge for some but that with feedback and revision, students can improve their writing.

To summarize my second goal, for writing educators, what this type of research can offer is another angle for teaching and analyzing source use with students. Often topics such as plagiarism, formatting, and the trilogy (paraphrasing, quoting and summary) overshadow these rhetorical aspects of external voice incorporation. Nevertheless, analyzing source use through the Appraisal framework, such as the categories provided in the Methods, could be a useful exercise to help students of all linguistic and cultural backgrounds understand the rhetorical value of source incorporation while also learning the linguistic techniques for using sources. In any writing class or research on writing, using the framework of the academic text as a dialogue of voices can be a useful starting point for introducing the categories of evaluative analysis.

\section{Conclusion}

Writers can use external voice in dialogically expansive ways, such as through acknowledging someone else's propositions while also integrating the external voice. Perhaps not surprisingly, some deny that a statement can ever be neutrally stated, even if in a larger 
rhetorical context; White and the Appraisal Website ("Modelling engagement," 2015) title the discussions on the non-existence of bare assertions as "no more facts." Any type of information from an outside source, even reporting a statistic, involves an evaluation from the authorial voice, even if subtle. This idea has been recognized by others as well from the Appraisal framework (Hu \& Wang, 2014) and other perspectives (Charles, 2006; Thompson \& Ye, 1991). Given this understanding, incorporating sources is not just a question of selecting between a paraphrase and a quotation, or using a certain school of formatting. Rather, writing an academic text involves a complex orchestration of ideas and voices while demanding a linguistic mastery to clearly identify ownership(s) of such ideas and words. Students, in many ways novice writers, whether ESL or mainstream, find such a task challenging. Appraisal and Engagement offer useful ways to analyze texts in order to understand the linguistic mechanics of such orchestrations.

Competing interests

The authors declare that they have no competing interests.

\section{Publisher's Note}

Springer Nature remains neutral with regard to jurisdictional claims in published maps and institutional affiliations.

Received: 21 May 2017 Accepted: 23 August 2017

Published online: 31 August 2017

\section{References}

Allison, Desmond. 1995. Assertions and alternatives: Helping ESL undergraduates extend their choices in academic writing. Journal of Second Language Writing 4 (1): 1-15.

Bakhtin, Mikhail. 1981. The dialogic imagination: Four essays. Austin: University of Texas Press.

Bakhtin, Mikhail. 1986. The problem of speech genres. In Speech genres and other late essays, ed. Caryl Emerson and Michael Holquist, 60-102. Austin: University of Texas Press.

Cao, Feng, and Guangwei Hu. 2014. Interactive metadiscourse in research articles: A comparative study of paradigmatic and disciplinary influences. Journal of Pragmatics 66: 15-31. doi:10.1016/j.pragma.2014.02.007.

Charles, Maggie. 2006. The construction of stance in reporting clauses: A cross-disciplinary study of theses. Applied Linguistics 27 (3): 492-518. doi:10.1093/applin/aml021.

"Dialogistic expansion and contraction." 2015. The appraisal website developed by Peter R.R. White. Retrieved from http://www.grammatics.com/appraisal/appraisalguide/framed/stage5-engagement-09.htm [Accessed 24 Aug 2017]

"Engagement," 2015. The appraisal website developed by Peter R.R. White. Retrieved from http://www.grammatics. com/appraisal/appraisaloutline/framed/appraisaloutline-08.htm\#P103_24481 [Accessed 24 Aug 2017]

"Engagement- a Bakhtinian perspective." 2015. The appraisal website developed by Peter R.R. White. Retrieved from http://www.grammatics.com/appraisal/appraisaloutline/framed/appraisaloutline-15.htm\#P223_49186. [Accessed 24 Aug 2017]

Gu, Qing, and Jane Brooks. 2008. Beyond the accusation of plagiarism. System 36 (3): 337-352. doi:10.1016/j.system. 2008.01.004.

Halliday, Michael Alexander Kirkwood. 1994. An introduction to functional grammar. London: Edward Arnold.

Hood, Susan. 2004. Managing attitude in undergraduate academic writing: A focus on the introductions to research reports. In Analyzing academic writing: Contextualized frameworks, ed. Louise Ravelli and Robert Ellis, 24-44. London: Continuum.

Hu, Guangwei, and Guihua Wang. 2014. Disciplinary and ethnolinguistic influences on citation in research articles. Journal of English for Academic Purposes 14: 14-28. doi:10.1016/j.jeap.2013.11.001.

Hutchings, Catherine. 2014. Referencing and identity, voice and agency: Adult learners' transformations within literacy practices. Higher Education Research \& Development 33 (2): 312-324. doi:10.1080/07294360.2013.832159.

Hyland, Ken. 1994. Hedging in academic writing and eap textbooks. English for Specific Purposes 13 (3): 239-256.

Hyland, Ken. 2000. Disciplinary discourses: Social interactions in academic writing: New York: Pearson education.

Hyland, Ken. 2004. Patterns of engagement: Dialogic features and L2 undergraduate writing. In L. Ravelli \& R. Ellis (Eds.) Analyzing academic writing: contextualized frameworks (pp. 5-23). London: Continuum.

Hyland, Ken. 2005. Stance and engagement: A model of interaction in academic discourse. Discourse Studies 7 (2): 173-192. doi:10.1177/1461445605050365.

Lee, Sook Hee. 2010. Attribution in high- and low-graded persuasive essays by tertiary students. Functions of Language 17 (2): 181-206.

Martin, James Robert \& Rose, David 2003. Working with Discourse: Meaning Beyond the Clause. London: Continuum. Martin, James Robert \& White, Peter Robert Rupart (2005). The language of evaluation: Appraisal in English. New York: Palgrave Macmillan.

Mei, Wu Siew. 2007. The use of engagement resources in high- and low-rated undergraduate geography essays. Journal of English for Academic Purposes 6 (3): 254-271.

Mei, Wu Siew, and Desmond Allison. 2005. Evaluative expressions in analytical arguments: Aspects of appraisal in assigned english language essays. Journal of Applied Linguistics 2 (1): 105-127. 
"Modelling engagement." 2015. The Appraisal Website. Retrieved from http://www.grammatics.com/appraisal/ appraisaloutline/framed/appraisaloutline-16.htm\#P246_59715 [Accessed 24 Aug 2017]

Petrić, Bojana. 2012. Legitimate textual borrowing: Direct quotation in L2 student writing. Journal of Second Language Writing 21 (2): 102-117. doi:10.1016/j.jslw.2012.03.005.

Swales, John M. 1990. Genre analysis: English in academic and research settings. Cambridge: Cambridge University Press.

Swales, John M. 2014. Variation in citational practice in a corpus of student biology papers: From parenthetical plonking to intertextual storytelling. Written Communication 31 (1): 118-141. doi:10.1177/0741088313515166.

"The appraisal website" (2015). Retrieved from http://www.grammatics.com/appraisal/ [Accessed 24 Aug 2017].

Thompson, Geoff, and Yiyun Ye. 1991. Evaluation in the reporting verbs used in academic papers. Applied Linguistics 12 (4): 365-382

White, Peter Robert Rupart. 2003. Beyond modality and hedging: A dialogic view of the language of intersubjective stance. Text 23 (2): 259-284.

Submit your manuscript to a SpringerOpen ${ }^{\circ}$ journal and benefit from:

- Convenient online submission

- Rigorous peer review

- Open access: articles freely available online

- High visibility within the field

- Retaining the copyright to your article

Submit your next manuscript at $\gg$ springeropen.com 